\title{
O ENSINO de hISTÓRIA PARA A EDUCAÇÃo DE JOVENS E ADULTOS NA ANPUH-BRASIL (1961-2015)
}

\author{
THE HISTORY TEACHING TO YOUTH AND ADULT EDUCATION AT ANPUH-BRASIL \\ (1961-2015)
}

Claudia Smuk da Rocha ${ }^{1}$

Iône Inês Pinsson Slongo ${ }^{2}$

\begin{abstract}
RESUMO: Apresenta-se o estado do conhecimento sobre o Ensino de História (EH) na Educação de Jovens e Adultos (EJA), entre produções acadêmicas socializadas nos Simpósios Nacionais da Associação Nacional de História (ANPUH-Brasil), realizados entre 1961 e 2015. Este estudo bibliográfico, de caráter exploratório, analisou 40 produções, à luz da epistemologia de Fleck (2010), particularmente das categorias "coletivo de pensamento", "estilo de pensamento" e "circulação intracoletiva e intercoletiva de ideias". Além das principais características da produção, a pesquisa evidenciou que problematizações sobre o EH na EJA emergiram nos Simpósios da ANPUHBrasil em 1971, apresentando uma lacuna até o final da década de 1990. A partir daí, tiveram presença contínua no evento, conquistando em 2015 um Simpósio Temático (ST) específico. Argumenta-se, com apoio na epistemologia fleckiana, que a presença crescente de produções, o desenvolvimento de pesquisas em Programas de Pós-Graduação e a realização de um ST específico sinalizam a gênese de um coletivo de pensamento focado no Ensino de História para a EJA.
\end{abstract}

Palavras-chave: Educação de Jovens e Adultos. Ensino de História. ANPUHBrasil. Epistemologia de Fleck.

\begin{abstract}
Presents the state of knowledge on the History Teaching (EH) in Youth and Adult Education (EJA), among academic productions socialized in the Symposiums of the Associação Nacional de História (ANPUH-Brasil), happened between 1961 and 2015. This bibliographic and exploratory study analyzed 40 productions, based on the epistemology of Fleck (2010), particularly of the categories "collective of thought", "style of thought" and "intracollective and intercollective circulation of thought". Besides the main characteristics of the productions, the research showed that problematizations related to EH in EJA emerge in Symposiums of the ANPUH-Brasil in 1971, what follows is a gap until the end of the 1990s. Since then, the productions with this approach had constant presence at the event, been intensified after the second decade of the XXI century, and gaining a Theme Symposium (ST)
\end{abstract}

\footnotetext{
1 Mestra em Educação pela Universidade Federal da Fronteira Sul (UFFS), Campus Chapecó/SC. Licenciada em História pela Universidade Regional Integrada do Alto Uruguai e das Missões (URI), Campus Erechim/RS. Professora do Sistema Municipal de Ensino de Erechim, atuando na EJA.

2 Doutora em Educação pela Universidade Federal de Santa Catarina (UFSC). Professora Adjunta da Universidade Federal da Fronteira Sul (UFFS), atuando no curso de Pedagogia e no Programa de Pós-Graduação em Educação da UFFS, Campus Chapecó.
} 
specific in 2015. It is argued, with support in Fleck's epistemology, that the increasing presence of productions, the development of research in Graduate Programs and the realization of a specific ST signal the genesis of a collective of thought focused on History Teaching for the EJA.

Keywords: Youth and Adult Education. History Teaching. ANPUH-Brasil. Fleck's Epistemology.

\section{Introdução}

O presente artigo deriva de um estudo ${ }^{3}$ que articulou duas dimensões educacionais brasileiras que cumprem importante função social: a Educação de Jovens e Adultos (EJA) e o Ensino de História (EH).

Inicialmente chamada de Educação de Adultos, a EJA foi criada para servir como um paliativo ao problema do analfabetismo no Brasil. Em sua complexa trajetória histórica, assumiu diferentes formatos, objetivos e finalidades, permeados por distintas concepções educacionais. Não obstante o seu reconhecimento como modalidade de Ensino da Educação Básica pela Lei de Diretrizes e Bases da Educação Nacional, a Lei no 9394/96, e o tímido avanço das políticas e programas para a ampliação da oferta de vagas, sobretudo a partir dos primeiros anos do século XXI, esta modalidade de caráter "provisório" ainda está longe de ser desnecessária.

Conforme os últimos dados sobre a demanda da EJA, embora "[...] a taxa de analfabetismo das pessoas com 15 anos ou mais vem sendo reduzida no Brasil: passou de 12,4\%, em 2001, para 8,7\%, em 2012" (BRASIL, 2014, p.37), o índice ainda permanece alto. Correspondia, à época, a cerca de 13,2 milhões de brasileiros, colocando o país na oitava posição do ranking mundial de analfabetismo. Além disso, até o ano de 2013, 87 milhões de brasileiros com mais de 15 anos não haviam completado seus estudos (CARA, 2014).

Contudo, a função social da EJA vai além de cumprir essa demanda por vagas para o acesso/retorno ao processo educacional formal. Uma vez ofertada, a EJA precisa também assegurar aos sujeitos a permanência nas instituições, por meio de uma aprendizagem significativa, oportunizando que avancem pelos diferentes níveis de ensino. É preciso levar em conta que os obstáculos que

\footnotetext{
${ }^{3}$ Dissertação defendida no Programa de Pós-Graduação em Educação da Universidade Federal da Fronteira Sul - UFFS (ROCHA, 2016).
} 
geram a demanda pela modalidade têm origem "[...] agora não mais devido a problemas de falta de escolas e vagas, mas [estão] relacionados, dentre outros fatores socioeconômicos, também ao processo de disseminação de conhecimento que ocorre nesses estabelecimentos de ensino" (DELIZOICOV, 2004, p.171).

As reflexões sobre as práticas pedagógicas na EJA e sobre o papel social da modalidade são pautas importantes no contexto atual, marcado pelo retrocesso das conquistas sociais dos brasileiros e por reformas que ameaçam os direitos dos sujeitos de aprendizagem da EJA, uma vez que estes fazem parte da classe trabalhadora.

No âmbito das práticas pedagógicas na EJA merece destaque o $\mathrm{EH}$, por seu papel na construção das identidades coletivas e enquanto instrumento de leitura crítica do mundo. O EH é um campo do conhecimento cuja trajetória está sendo construída há longa data no Brasil, por meio da atuação de uma comunidade nacional de investigadores, desde pelo menos 1957 (COSTA e OLIVEIRA, 2007). As reflexões deste campo também são de fundamental importância no cenário atual, onde forças conservadoras têm defendido um projeto de lei em trâmite na Câmara dos Deputados, o PL 246/19, que se coloca como uma afronta ao livre pensar e à função social do EH "[...] que é a capacitação dos indivíduos para procederem à leitura crítica do meio no qual realizam suas experiências individuais e coletivas" (CAIMI, 2001, p.114).

É na interface destes dois campos do conhecimento que se pretende contribuir, analisando a atenção dada à EJA pela comunidade nacional de pesquisadores em EH. Entretanto, visto a necessidade de delimitar o estudo, adotou-se como recorte os Simpósios Nacionais da Associação Nacional de História, a ANPUH-Brasil. Esta opção foi motivada porque este é considerado o "[...] maior e mais importante evento da área de História no país e na América Latina" (MESQUITA, 2008, p.122) e também porque a gênese da constituição do EH como campo de investigação foi contemporânea à fundação da Associação. ${ }^{4}$

A ANPUH-Brasil é uma sociedade científica com mais de meio século de atuação, fundada em 1961, no município de Marília/SP, durante o I Simpósio dos

\footnotetext{
${ }^{4}$ Cabe ressaltar que a atuação dos investigadores em EH não se restringe ao âmbito da ANPUHBrasil. Os pesquisadores do campo do $\mathrm{EH}$ buscaram construir outros espaços para o debate acadêmico, criando, por exemplo, o Seminário Perspectivas do Ensino de História (1988) e o Encontro Nacional dos Pesquisadores em Ensino de História - ENPEH (1993).
} 
Professores de História do Ensino Superior, ainda com a sigla APUH, referindo-se à Associação dos Professores Universitários de História. Em 1971, com a intensificação das atividades e a criação dos núcleos regionais, foi acrescida a palavra "Nacional", passando então a utilizar a sigla ANPUH. Em 1993 a entidade suprimiu de sua nomenclatura o termo "Professores Universitários", mantendo o acrograma. A partir de 2011, passou a identificar-se como ANPUH-Brasil.

Realizado com regularidade bienal, o evento chegou em 2015 à 28a edição, com a realização do XXVIII Simpósio Nacional de História (SNH), em Florianópolis/SC. ${ }^{5}$ A metodologia de socialização da produção científica da área foi se transformando à medida que os Simpósios aumentavam. Contudo, desde as primeiras reuniões os trabalhos socializados assumem o formato de artigos, apresentados oralmente, denominados pelos organizadores de "Comunicações".

Nas primeiras reuniões, a socialização das Comunicações ocorria em "sessões de estudos", com temas previamente definidos e entregues aos Grupos de Trabalho, que conjuntamente a produziam, sendo apresentada por um relator e aberta ao debate. A partir do V Simpósio (1969), o evento passou a realizar "sessões simultâneas", em função da expansão dos núcleos regionais e da elevação no número de participantes. Em 1977, surgiu a proposta de que professores secundários e estudantes universitários pudessem apresentar Comunicações e intervir nos debates. O pleito pela aceitação de professores secundários como sócios provocou calorosos debates, resultando na dissidência de alguns membros da Associação, que fundaram outra sociedade científica.

Na década de 1980 o volume de produções se expandiu e a dinâmica de socialização passou a contar com sessões de "Comunicações Livres" e de "Comunicações Coordenadas", onde as produções se relacionavam a temáticas específicas e contavam com professores-pesquisadores como mediadores dos debates. Desde 2003 as Comunicações começaram a ser apresentadas em Simpósios Temáticos (ST), cujos proponentes são pesquisadores com experiência investigativa nos temas e também cumprem o papel de mediadores nos debates.

\footnotetext{
5 À época da conclusão da pesquisa, esse havia sido o último Simpósio Nacional de História (SNH). Em 2017 realizou-se o XXIX SNH, em Brasília/DF. No ano de 2019, Recife/PE sediou o XXX SNH.
} 
Existe um vasto acervo de produções apresentadas no evento, disponibilizado em meio eletrônico. ${ }^{6}$ Portanto, além da grande circulação de produção científica, outro aspecto que favoreceu a pesquisa foi o fácil acesso ao material empírico. Assim, partiu-se da seguinte questão: Qual o lugar ocupado pela produção sobre o Ensino de História na EJA nos Simpósios Nacionais da ANPUH-Brasil e que características apresentam as produções sobre o tema disseminadas neste espaço?

Uma vez que o objeto da pesquisa envolveu interações entre os sujeitos que produziram e compartilharam o conhecimento nos SNH, buscou-se apoio epistemológico em Ludwik Fleck (2010). Sua teoria da ciência oferece categorias que privilegiam o olhar histórico e sociológico para a análise da produção e disseminação do conhecimento, tais como "coletivo de pensamento", "estilo de pensamento" e "circulação intracoletiva e intercoletiva de ideias".

Em seus resultados, a pesquisa sinalizou os protagonistas da problematização sobre o EH na EJA nos Simpósios da ANPUH, bem como as principais características da produção, de acordo com as seguintes categorias analíticas definidas: formação acadêmica/atuação profissional dos autores e o pertencimento a "coletivos de pensamento"; referenciais teóricos e metodológicos compartilhados; núcleos temáticos; natureza acadêmica das produções; concepções de Ensino de História e de EJA; e linguagem específica.

A título de considerações finais, foi possível argumentar que a estrutura social científica que começa a se organizar em torno das problemáticas do $\mathrm{EH}$ na EJA pode significar a gênese de um coletivo de pensamento com o interesse voltado prioritariamente para este foco.

\section{A investigação sobre o lugar do Ensino de História na EJA nos} Simpósios Nacionais da ANPUH-Brasil: elementos teórico-metodológicos

\footnotetext{
${ }^{6}$ À época, os anais podiam ser encontrados no portal "http://anais.anpuh.org/", bem como sites individualizados, relativos às últimas edições dos SNH: "http://snh2011.anpuh.org", "http://snh2013.anpuh.org", e "http://snh2015.anpuh.org". Atualmente, os anais de todas as edições do evento estão disponíveis no site "https://anpuh.org.br/index.php/documentos/anais".
} 
A metodologia implicou no levantamento, sistematização e análise da produção sobre o EH na EJA que circulou nos SNH, realizados entre 1961 e 2015, cobrindo mais de cinco décadas de intensa atividade científica. Em função deste recorte, este estudo bibliográfico, de caráter exploratório, adotou o enfoque metodológico do "estado do conhecimento" (FERREIRA, 2002; ROMANOWSKI; ENS, 2006), por realizar o levantamento e a análise de apenas um setor das publicações, diferenciando-se das pesquisas do tipo "estado da arte", que procuram contemplar as diversas fontes disponíveis sobre o tema investigado.

Já o referencial metodológico escolhido para dar suporte à organização e análise preliminar do material empírico foi a Análise de Conteúdo, proposta por Bardin (2002). Também foram utilizadas contribuições de Triviños (1987), que ofereceu uma síntese dos princípios e procedimentos desta abordagem.

A fonte que forneceu o material empírico foi a Plataforma "Anais ANPUH", ferramenta de pesquisa virtual que disponibilizava todos os Anais dos $\mathrm{SNH}$, desde 1961 até 2009, bem como sites individualizados que armazenam a produção socializada nos eventos de 2011, 2013 e 2015. Realizou-se a busca utilizando as palavras e expressões presentes na trajetória histórica da modalidade: Educação de Jovens e Adultos, Educação de Adultos, Educação Popular, Ensino Supletivo, Alfabetização de Adultos, Paulo Freire, Método Paulo Freire, MOBRAL e Madureza. O uso de um número elevado de palavras e expressões de busca se mostrou necessário em função da mudança de nomenclatura da modalidade ao longo do tempo, como também, pela heterogeneidade dos objetos de estudo das produções socializadas nos SNH.

Esse levantamento inicial apontou 284 produções. No entanto, o dado não anunciou o resultado final da seleção, pois conforme iam se alternando as palavras e expressões na plataforma, muitas ocorrências se repetiam, assim como eram apontadas produções que não atendiam à delimitação do estudo.

Assim, na etapa da pré-análise, 49 repetições que a plataforma havia apontado foram descartadas. Em seguida, outras 98 produções foram desconsideradas, pois seus conteúdos não tinham relação com a modalidade de ensino investigada. Esta constatação se deu a partir de uma leitura "flutuante" dos resumos, quando da existência deste elemento, ou da introdução dos artigos. Esse tipo de leitura se caracteriza por "[...] estabelecer contato com os 
documentos a analisar, em conhecer o texto deixando-se invadir por impressões e orientações" (BARDIN, 2002, p.96).

Estes procedimentos de seleção apontaram para um conjunto de 138 produções, sobre as quais se realizou uma primeira organização, a partir da verificação de que a abordagem da EJA - e das demais palavras e expressões relacionadas à história da modalidade - se davam em três ênfases distintas:

- 40 produções com o ensino de História na EJA como objeto central;

- 66 produções resultantes de pesquisas no campo da História, sobre variadas temáticas (tais como História da Educação, de Movimentos Sociais, de Instituições, etc.), onde a EJA e demais nomenclaturas aparecem como "fatos" de diferentes conjunturas, como contexto ou realidade dos sujeitos de pesquisa;

- 32 produções com outros focos educacionais ou objetos da pesquisa em EH (tais como livros didáticos, currículo, formação de professores, questões metodológicas e epistemológicas, etc.), mas que incluíam os sujeitos da EJA.

O corpus da pesquisa ficou delimitado ao primeiro conjunto de produções, com 40 trabalhos (14 resumos e 26 artigos completos). Contudo, considerada a riqueza dos outros dois conjuntos, os mesmos foram organizados e apresentados em apenso ao relatório do estudo, a fim de auxiliar futuras pesquisas.

Ao discorrer sobre a "análise referencial", ou a última fase da análise de conteúdo, Triviños (1987, p.159) fez questão de "salientar que qualquer técnica [...] adquire sua força e seu valor exclusivamente mediante o apoio de determinado referencial teórico. E, naturalmente, a análise de conteúdo não foge a este enunciado geral". Sendo assim, o instrumental analítico construído buscou guarida teórica nas categorias centrais da epistemologia de Fleck (2010): "coletivo de pensamento" e "estilo de pensamento", e "circulação intracoletiva e intercoletiva de ideias.

Convém explicitar brevemente quem foi Ludwik Fleck e como se articulam as categorias acima citadas na teoria do conhecimento por ele desenvolvida. Fleck foi um médico, pesquisador em microbiologia, de origem judaico-polonesa, nascido em fins do século XIX. Foi um sobrevivente do holocausto da Segunda Guerra Mundial, depois de ter sido preso em campos de concentração e obrigado a trabalhar nos laboratórios nazistas por ser um renomado pesquisador do tifo. 
Paralelamente à suas atividades médicas e de pesquisa, Fleck se ocupou em refletir sobre a natureza da atividade científica. Segundo Löwy, (2012, p.14), por influência da Escola Polonesa de Filosofia da Medicina, no período entre 1926 e 1946, Fleck expressou ideias inovadoras sobre a ciência, desenvolvendo uma epistemologia própria. Destes estudos resultaram suas produções no campo da epistemologia, sendo a mais ampla e difundida a monografia publicada em 1935, intitulada Gênese e desenvolvimento de um fato científico. Tal obra "[...] aborda dois complexos de temas: no primeiro, o autor observa um estudo de caso da história da medicina, a saber, o desenvolvimento do conceito de sífilis. A partir daí, no segundo, examina suas deduções epistemológicas" (SCHÄFER; SCHNELLE, 2010, p.14).

Por meio desta análise histórico-epistemológica, Fleck (2010) trouxe importantes contribuições para a teoria da ciência, entre as quais as concepções do condicionamento histórico/social do conhecimento e do caráter coletivo da pesquisa científica, sobre as quais atuam as forças sociais. Segundo o autor, as comunidades científicas se estruturam em unidades sociais, os "coletivos de pensamento" de pesquisadores com interesses em comum. Os coletivos são portadores de um "estilo de pensamento", socialmente condicionado, resultado do desenvolvimento histórico dos saberes e que constituem uma rede de conceitos e pressupostos, formas de pensar e agir característicos, que estão em constante intercâmbio entre os indivíduos por meio da "circulação intracoletiva e intercoletiva de ideias". A evolução da ciência é resultado destas influências recíprocas, que favorecem a emergência de novos problemas.

A partir destas premissas fleckianas, foi construído um instrumental analítico adequado à pesquisa aqui relatada. Vale ressaltar que o epistemólogo "[...] se dirige não apenas ao especialista em teoria da ciência, mas também escreve uma introdução na sua nova teoria do 'estilo de pensamento' e do 'coletivo de pensamento', que visava alcançar um amplo público com interesses científicos" (SCHÄFER; SCHNELLE, 2010, p.2), sendo, portanto, profícua também na análise dos processos de produção e disseminação do conhecimento nos campos do EH e da EJA.

Assim, a primeira categoria analítica construída investigou a formação acadêmica/atuação profissional dos autores e o pertencimento a "coletivos de 
pensamento". Isso porque o processo formativo é um fator bastante revelador acerca do "coletivo de pensamento" ao qual pertence um pesquisador. Para Fleck (2010, p.85), "[...] qualquer aprendizagem é continuação de uma tradição e de uma sociedade $[\ldots] "$. . A educação, a tradição e o hábito, são fatores que o autor apontou como os principais responsáveis por direcionar o olhar e orientar as ações de um indivíduo de acordo com um estilo de pensamento.

A segunda categoria analítica identificou os referenciais teóricos compartilhados pelos autores das produções. Estes sinalizaram as bases, fundamentos e concepções em que estão ancoradas. De acordo com a epistemologia de Fleck (2010), um dos elementos constitutivos de um estilo de pensamento são os conhecimentos compartilhados no interior de um coletivo de pensamento ou na inter-relação de mais coletivos. Estes pressupostos influenciam o modo de elaborar e tratar os problemas de pesquisa. Para Fleck (2010), um "fato científico" não existe por si mesmo, mas somente no interior de leis, crenças e valores que emergem de uma perspectiva teórica compartilhada.

Outro critério de aproximação com o material empírico foram os núcleos temáticos privilegiados. As escolhas dos autores ao construírem seus objetos de estudo revelam as tendências sobre o $\mathrm{EH}$ na EJA, e evidenciam as mudanças e permanências ao longo do período estudado. Segundo a epistemologia de Fleck (2010), quando um pesquisador constrói seu objeto de análise, ele o faz influenciado pelo "estado do saber" já existente na área, bem como pelo seu processo formativo, que transcende a vontade própria. Esse olhar direcionado é o aspecto fundamental entre os elementos constituintes de um estilo de pensamento e também interfere na forma como o pesquisador concebe e trata problemas. Além disso, existem as forças sociais, que também exercem influência na definição de objetos de pesquisa.

A natureza das produções foi uma categoria analítica que permitiu identificar o tipo de trabalho acadêmico que originou cada um dos artigos e resumos do corpus da pesquisa. Para embasar o agrupamento do material empírico segundo este critério, utilizou-se o estudo de Soares e Maciel (2000), emprestando deste a noção de "natureza" da produção, bem como as categorias que dela emergem: "Ensaio", "Relato de experiência" e "Pesquisas" (SOARES; MACIEL, 2000). A natureza acadêmica das produções é reveladora dos diferentes 
níveis e espaços acadêmicos onde tem existido a preocupação em discutir o EH na EJA, indo de encontro ao "[...] postulado fleckiano de que a circulação de ideias é uma fonte de novos significados e ideias e, portanto, de inovação da ciência" (SLONGO, 2004, p.142).

Por fim, o estudo da produção sobre o EH na EJA disseminada nos SNH contou ainda com categorias analíticas complementares: as concepções de EJA e de EH e a linguagem específica. Na epistemologia de Fleck (2010), estas categorias são elementos constitutivos de um estilo de pensamento. De acordo com o autor,

\footnotetext{
As concepções não são sistemas lógicos - por mais que queiram sê-lo -, mas unidades estilísticas, que se desenvolvem e regridem como tais ou transitam para outras unidades com suas provas. Cada época tem concepções dominantes, restos das concepções passadas e predisposições de concepções futuras, em analogia com todas as formas sociais (FLECK, 2010, p.70).
}

Já a linguagem tem papel fundamental na construção do conhecimento e na dinâmica científica, segundo Fleck (2010). O autor definiu os coletivos de pensamento como unidades sociais onde "Dispositivos legais e costumários, linguagens específicas, em alguns casos, ou pelo menos um vocabulário peculiar, fecham a comunidade de pensamento formalmente, mesmo se não for de maneira absoluta" (FLECK, 2010, p.155). Portanto, a linguagem é um elemento que indica que um grupo é portador comunitário de um "estilo de pensamento".

\section{Onsino de História na EJA como objeto de investigação das produções socializadas nos Simpósios Nacionais da ANPUH-Brasil}

Os primeiros resultados obtidos da análise da produção sobre o Ensino de História na EJA, socializada nos SNH, foram fruto de uma "descrição analítica", tal como Triviños (1987) denominou a segunda fase da análise de conteúdo, onde, segundo o autor, o estudo sobre o material que constitui o corpus da pesquisa começa a ser observado em maior profundidade. Assim, foram traçados aspectos gerais da amostra de trabalhos, constituída de 40 produções. 
A partir desta análise preliminar foi possível verificar que 07 das 40 produções levantadas foram escritas em coautoria, envolvendo assim, um total de 51 pessoas. Sobre o gênero dos autores, os dados revelaram que a maioria é do sexo feminino. Entre as 51 pessoas envolvidas na escrita das produções, 35 eram mulheres, o que representa 68,6\%. A predominância feminina na discussão sobre o EH na EJA segue a tendência observada por um estudo que analisou as produções no campo de investigação em EH, veiculadas em publicações editoriais e em periódicos científicos, entre as décadas de 1980 e 1990, no qual a autora considerou "[...] que esse fenômeno se explica pelo próprio objeto de estudo, havendo uma tradição em ver no gênero feminino maior habilidade para tratar das questões do ensino" (CAIMI, 2001, p.48).

Em relação às Instituições de Ensino Superior (IES) às quais os autores da produção estavam vinculados à época da socialização, a com maior representatividade foi a Universidade Federal de Santa Catarina (UFSC), apresentando 04 ocorrências. Foram 07 as IES que apareceram em segundo lugar em termos de representatividade, sendo que cada uma delas foi citada por dois autores: Universidade do Estado da Bahia (UNEB), Universidade Federal do Rio de Janeiro (UFRJ), Universidade Federal de Minas Gerais (UFMG), Universidade Federal de Goiás (UFG), Universidade Federal de São Paulo (USP), Universidade Federal do Rio Grande do Norte (UFRN) e Universidade Federal da Paraíba (UFPB). Outras 16 Instituições, não só de Ensino Superior, foram mencionadas apenas uma vez.

A análise da distribuição geográfica das produções revelou que a unidade da Federação que mais produziu sobre o EH na EJA nos SNH foi Santa Catarina, que além dos quatro vinculados à UFSC, possui outro autor representando o Instituto Federal de Santa Catarina (IFSC), totalizando 05 produções. Em seguida, a maior produção se concentrou na Bahia (com duas produções da UNEB e uma da Universidade Estadual de Feira de Santana - UEFS) e no Rio de Janeiro (duas da UFRJ e uma da Universidade Federal Fluminense - UFF).

Embora um estado da região Sul tenha se destacado na análise da distribuição da produção por unidades da Federação, no agrupamento por regiões do país, a que concentrou maior produção foi a região Nordeste, com 13 trabalhos (32,5\% das produções localizadas). Em segundo lugar ficou a região 
Sudeste, com 10 trabalhos (25\% das produções), e em seguida a região Sul, apresentando um total de 07 trabalhos (17,5\% do universo de produções). $\mathrm{Na}$ região centro-oeste concentraram-se 06 trabalhos (15\% das produções). A maior região do Brasil, a Norte, apareceu com apenas 01 trabalho (2,5\% das produções). Dois autores não forneceram os dados da IES que representavam e uma delas não foi identificada. Isto é, 03 trabalhos não puderam ser distribuídos geograficamente $(7,5 \%$ do total de produções levantadas).

O destaque da região Nordeste apresenta coerência com a trajetória histórica da modalidade de ensino. O Nordeste foi palco, no início da década de 1960, de práticas significativas na educação de adultos, tais como a Campanha de pé no chão também se aprende a ler, e a experiência de Angicos/RN, liderada por Paulo Freire (GADOTTI, 2014). Estas iniciativas, pautadas numa concepção libertadora da educação, se realizaram no Nordeste porque historicamente esta é a região com a maior demanda pela EJA, permanecendo a região com o maior número de pessoas com 15 anos ou mais que não sabem ler nem escrever: "Todos os estados da Região Nordeste apresentaram taxas de analfabetismo mais elevadas que os $8,7 \%$ verificados para a média brasileira. Em 2012, a taxa para a região foi de 17,4\%" (BRASIL, 2014, p.37).

Duas capitais da região Nordeste - Fortaleza e Natal - foram sedes dos SNH. Em Fortaleza/CE, em 2009, foram apresentadas 04 produções, enquanto em Natal/RN, em 2013, foram 13. Juntas, as produções apresentadas nos eventos das duas capitais nordestinas significam 42,5\% do total de produções localizadas. A Figura 1 demonstra como o total de produções que abordam o $\mathrm{EH}$ na $\mathrm{EJA}$ se distribuiu ao longo dos $\mathrm{SNH}$, realizados nos anos descritos no eixo $\mathrm{x}$ :

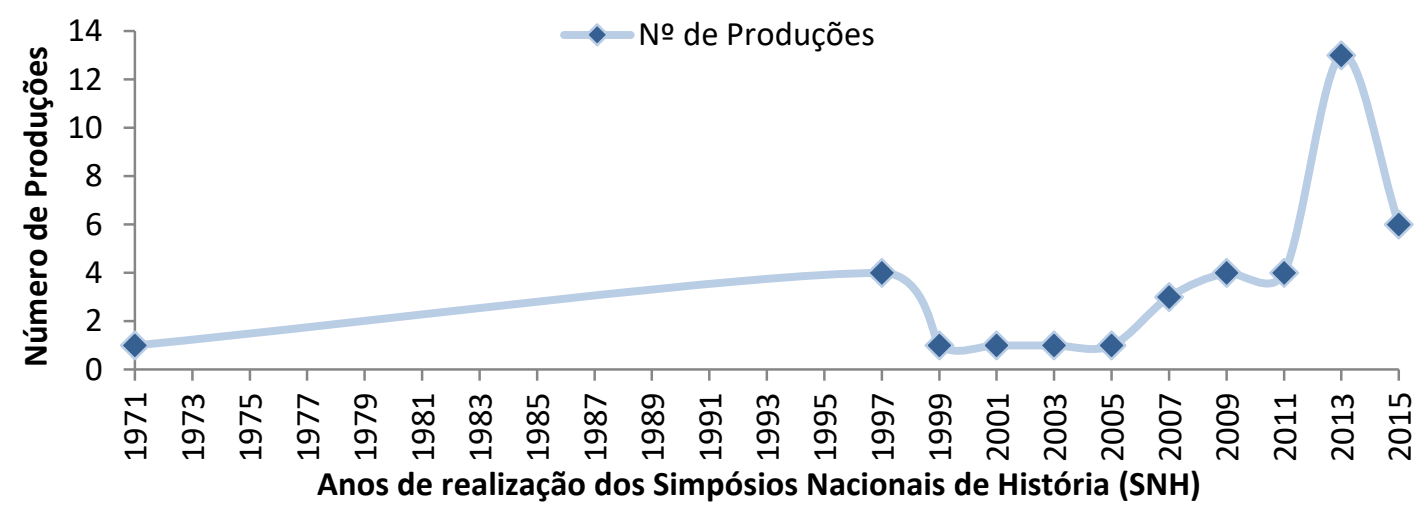

Figura 1: Movimento das produções sobre EH na EJA nos SNH 
O estudo revelou que o movimento das produções sobre o $\mathrm{EH}$ na EJA nos SNH despontou em 1971, uma década após a realização do primeiro Simpósio. Depois disso, se evidencia uma grande lacuna que perpassa as décadas de 1970 e 1980. A completa ausência da abordagem sobre o EH na EJA ao longo da década de 1980 causa uma inquietação, pois segundo Reis (2001), por essa época, a teoria da História Social já contava com a adesão de muitos profissionais da área no Brasil:

\begin{abstract}
Na década de 80 , não só a História Social se afirmou no campo da Historiografia, como uma produção significativa nos principais centros difusores de pesquisa, como também surgiu nas instituições universitárias brasileiras um número cada vez mais representativo de trabalhos na direção apontada pela História Social, ampliando-se e difundindo-se, nas séries fundamentais de ensino, a preocupação de professores com a discussão de suas práticas, na busca de um repensar constante do conhecimento histórico (REIS, 2001, p.12).
\end{abstract}

A abordagem da História Social foi responsável por incluir sujeitos que estavam à margem da História, como camponeses, operários, mulheres, escravos, indígenas, etc., e se sabe que era justamente entre essas classes que se concentrava a demanda pela alfabetização e escolarização por meio da modalidade que hoje se denomina EJA. Por isso o estranhamento de não encontrar referências à EJA, mesmo considerando suas nomenclaturas anteriores, entre este conjunto de produções.

$\mathrm{O} \mathrm{EH}$ na EJA só passou a figurar de forma contínua e crescente nos SNH a partir do final dos anos 1990. No XVIII Simpósio, realizado em 1995, timidamente a temática da EJA começa a marcar presença, com a realização da sessão de Comunicações Coordenadas no 0091, intitulada $O$ pensamento católico e a problemática dos excluídos: a educação de base e a alfabetização de adultos.

No XIX Simpósio, em 1997, realizou-se uma Sessão de Comunicações Livres (SCL130) denominada Experiências de Ensino com Jovens e Adultos. Uma justificativa para este despertar para as problemáticas relacionadas ao EH na EJA no final da década de 1990 foi a promulgação da Lei no 9394/96, que estabeleceu as Diretrizes e Bases da Educação, e que passou a reconhecer a EJA como modalidade da educação básica. A partir do XX Simpósio, realizado em 
1999, a temática do EH na EJA apareceu de forma contínua entre as comunicações apresentadas.

Em 2013, na XXVII edição do evento, Paulo Eduardo Dias de Mello (UEPG) e Raimundo Nonato Araújo da Rocha (UFRN) foram proponentes de um Simpósio Temático (ST) dedicado exclusivamente à EJA. Conforme o site oficial do evento, o ST de número 116 intitulava-se O ensino de História na Educação de Jovens e Adultos: materiais didáticos, cultura escolar e identidades. ${ }^{7}$ Contudo, como mostram os Anais de 2013, o ST não se realizou e a explicação mais plausível para este fato é a de que as inscrições não tenham atingido a exigência mínima de 20 Comunicações. Assim, as produções localizadas foram apresentadas em outros ST relacionados ao $\mathrm{EH}$.

No ano de 2015, finalmente foi realizado o ST específico da EJA. Os proponentes foram Alessandra Nicodemos Oliveira Silva (UFRJ) e Paulo Eduardo Dias de Mello (UEPG), e o ST intitulava-se O Ensino de História e a Educação de Jovens e Adultos: materiais didáticos, currículos, práticas docentes e identidades. O número de trabalhos inscritos neste ST chegou a 20. No entanto, na etapa da pré-análise deste material, foi constatado que nem todos tratavam especificamente do EH na EJA. Alguns deles tinham como sujeitos de pesquisa estudantes do ensino regular, outros tratavam da história da modalidade. Em síntese, dos vinte trabalhos inscritos, apenas seis atenderam aos critérios de inclusão ao corpus da pesquisa. Este fator explica a redução em relação ao número de produções localizadas entre os Anais do SNH anterior, em 2013. Este dado também é revelador de que os pesquisadores do EH na EJA estão iniciando o processo de organização de uma unidade social em um ambiente acadêmico que, segundo a epistemologia de Fleck (2010), está permeado por intensa circulação intercoletiva de ideias.

A seguir, apresenta-se a terceira etapa da análise de conteúdo, ou a análise referencial do material empírico arrolado (40 produções, sendo 14 resumos e 26 artigos completos), realizada a partir das categorias explicitadas anteriormente (formação acadêmica dos autores, referenciais teóricos compartilhados, núcleos temáticos privilegiados e natureza acadêmica dos

\footnotetext{
${ }^{7}$ Informações disponíveis em: <http://www.snh2013.anpuh.org/simposio/view?ID_SIMPOSIO= $1258>$.
} 
trabalhos). A produção analisada abrange o período temporal de 1971 a 2015 (sendo que sua distribuição se configura em uma produção em 1971, quatro na década de 1990, e as demais no século XXI).

A primeira característica da produção investigada foi a formação acadêmica dos 51 autores. Verificou-se a predominância no campo da Educação, evidenciada pela soma dos autores que possuem como titulação máxima o doutorado, mestrado ou graduação na área (25 autores, o que significa 49\% do total), que ultrapassou discretamente a área de História (20 autores, representando 39,2\%). Esse dado não significou, no entanto, que esta produção em Educação estivesse desvinculada da ciência referência, a História. Isso porque mais de $50 \%$ dos autores que possuíam doutorado em Educação tiveram sua formação inicial em cursos de licenciatura e/ou bacharelado em História. Entre os oito autores que possuíam o título de mestre em Educação, sete tinham formação inicial em História.

A análise da formação acadêmica permitiu inferir que a maioria dos autores eram conhecedores do estatuto epistemológico da História, e que suas produções, estando em interface com o conhecimento do campo da Educação, harmonizam com as produções em Ensino de História. Como observou Mesquita (2008, p.233), este campo de investigação "[...] vem, ao longo dos anos de 1980, 1990 e agora no século XXI, construindo-se numa zona intersticial, num lócus fronteiriço [...] dos campos da História e a Educação, que dialogam entre si e com outras áreas do conhecimento".

A diversidade na trajetória acadêmica dos autores e a multidisciplinaridade que envolve a produção, analisada a partir da epistemologia de Fleck (2010), evidenciou uma intensa circulação intercoletiva de ideias. Este dado foi significativo para o estudo, já que, de acordo com este referencial, "[...] está no diálogo entre distintos campos do saber a origem de novas ideias e, portanto, a mais importante alternativa capaz de levar um campo do conhecimento à transformação" (SLONGO, 2004, p.171). Nesta fase de grande intercâmbio de ideias são definidos especialmente os objetos de estudo, os conhecimentos e práticas orientadores da pesquisa, contribuindo, assim, para a instauração de um novo estilo de pensamento, decorrente de outros, nos quais os pesquisadores construíram sua formação. 
Já o levantamento dos referenciais teóricos que subsidiaram as pesquisas revelou a presença de mais de 160 diferentes autores nas 40 produções sobre o $\mathrm{EH}$ na EJA que circularam nos SNH. O autor mais citado foi Paulo Freire. É importante pontuar que foram encontradas produções que não explicitaram entre os referenciais as obras de Freire, mas que em suas entrelinhas foi possível captar a influência do pensamento freiriano, pois utilizavam expressões como "práxis educativa", "conhecimento científico e conhecimento popular em comunhão", "diálogo da experiência de vida e da prática escolar", que os sujeitos da EJA constituem um "público afetuoso", entre outras. Em seguida, o referencial teórico mais recorrente foram obras de Circe Maria Fernandes Bittencourt, do campo do Ensino de História.

Muitos outros autores do campo do EH subsidiaram a produção analisada: Selva Guimarães Fonseca, Holien Gonçalves Bezerra, Maria Auxiliadora Moreira dos Santos Schmidt, Ana Maria Ferreira da Costa Monteiro, Luis Fernando Cerri, Lana Mara de Castro Siman e Kátia Maria Abud. Também foram mencionados trabalhos do campo do $\mathrm{EH}$ realizados em coautoria, como as parcerias entre Selva Guimarães Fonseca e Marcos Silva, Jaime Pinsky e Carla B. Pinsky e Maria Auxiliadora Schmidt e Marlene Cainelli. Outros nomes relevantes do campo do EH apareceram citados apenas uma vez: Déa Ribeiro Fenelon, Maria Margarida Dias Oliveira, José Ricardo Oriá, Conceição Cabrini, Sônia L. Nikitiuk, Helenice Ciampi, Ubiratan Rocha, Kasumi Munakata e Antônio Fávero Sobrinho.

Entre os referenciais figuraram também os teóricos da EJA. Miguel Arroyo ficou em terceiro lugar entre os mais citados. Outros referenciais compartilhados deste campo foram: Moacir Gadotti, Álvaro Vieira Pinto, Leôncio José Gomes Soares, Inês Barbosa de Oliveira, Nilma Lino Gomes, Sérgio Haddad e Maria Clara Di Pierro. Também existiram importantes nomes deste campo citados em apenas uma produção: Marta Kohl de Oliveira, Claudia Lemos Vóvio, Magda Soares, Irene Terezinha Fuck, Jane Paiva, Osmar Fávero, Maria Hermínia Lage Fernandes Laffin, José Eustáquio Romão e João Luiz Máximo da Silva. Foram compartilhados ainda referenciais do campo da Educação que não têm como foco de sua produção nem o EH e nem a EJA, como Dermeval Saviani, José Carlos Libâneo, Carlos Ramos Mota e Najla Veloso Sampaio Barbosa. 
Dentre os autores nacionais, há os que subsidiaram metodologicamente as produções, como Marli André e Menga Ludke (Pesquisa em Educação: abordagens qualitativas) e Carlos Rodrigues Brandão (Pesquisa Participante). Um autor do campo do EH, Luis Fernando Cerri, subsidiou uma produção através de um instrumento de coleta de dados. O embasamento metodológico predominante explicitou a articulação com referenciais da pesquisa qualitativa, dado indicativo da existência de concepções e práticas de pesquisa compartilhadas, que segundo a epistemologia de Fleck (2010), são elementos constitutivos de um estilo de pensamento.

Já o número de referenciais internacionais compartilhados evidenciou uma menor incidência destes em relação ao quantitativo de autores nacionais. Entre os autores do campo da História, figuraram teóricos ligados a diversas correntes historiográficas. A Escola dos Analles apareceu representada por Jacques Le Goff. A História Social inglesa subsidiou teoricamente as produções por meio das contribuições de Edward P. Thompson e Eric Hobsbawm. Já entre os referenciais teóricos associados à Nova História estavam Michel de Certeau e Pierre Nora. A historiografia alemã também apareceu entre os referenciais compartilhados, representada por Jörn Rüsen. Foram citados apenas uma vez nomes da historiografia francesa (Marc Bloch, Roger Chartier, Fernand Braudel, François Hartog), da historiografia inglesa (Raymond Williams) e alemã (Reinhart Kosellek). Os autores estrangeiros do campo do EH citados apenas uma vez foram os espanhóis Joaquin Prats, Raimundo Cuesta Fernandez e Francisco Javier Merchán Iglesias.

No campo da Educação, os referenciais teóricos internacionais compartilhados foram o canadense Maurice Tardif e os portugueses António Nóvoa e José Pacheco. Outros importantes nomes deste campo foram citados apenas uma vez: Gimeno Sacristán, Ivor F. Goodson, Philippe Perrenoud, Yves Chevallard, Bernard Charlot, Edgar Morin, Pierre Bourdieu e Jean Claude Passeron, Moisey Pistrak, Anne Marie-Chartier e John Dewey. Estas referências revelaram o ecletismo das concepções educacionais do conjunto da produção analisada, que abrange a teoria crítica, a crítico-reprodutivista, a pedagogia socialista e o construtivismo. 
Os referenciais compartilhados na área da Filosofia foram Karl Marx e Antonio Gramsci. Outros pensadores marxistas apareceram como referencial compartilhado, como o historiador e sociólogo jamaicano Stuart Hall, ou foram citados apenas uma vez: Walter Benjamin, Cornelius Castoriadis, Karel Kosik e Georg Lukács. Como referencial metodológico internacional apareceu o nome de Laurence Bardin, e sua difundida obra Análise de Conteúdo, reiterando a presença constante da abordagem qualitativa entre a produção analisada.

Os referenciais compartilhados revelaram que $\mathrm{O} E \mathrm{H}$ na $E J A$ está predominantemente ancorado em fundamentos críticos da Educação e da História. Como preconizou Fleck (2010), a perspectiva teórica compartilhada estabelece um conjunto de crenças e valores, decisivos na construção das concepções de História e de Educação, bem como na forma como os autores tratam os problemas referentes à EJA. A linguagem específica que emergiu a partir destas influências, outro elemento constitutivo do estilo de pensamento para Fleck (2010), apontou para a concepção de História como "processo", "movimento" das coletividades, da Educação como "práxis", e da EJA como modalidade repleta de "especificidades".

No agrupamento da produção analisada em núcleos temáticos foi constatada a dispersão das 40 produções em 15 diferentes temas. O núcleo temático mais recorrente foi o que trata de questões acerca do currículo, sendo que a maior concentração de produções se deu no SNH de 2013, em Natal/RN, no qual o tema fundamental foi "Conhecimento Histórico e Diálogo Social", o que reflete a preocupação da Associação em repensar a disseminação e a função social do conhecimento histórico, e onde os autores encontraram ambiente propício para discutir as questões sobre "o que ensinar", e "em favor de que/quem ensinar". Deste conjunto de textos emergiram linguagens específicas como "currículo oculto", "lugar de disputa", "relações de poder", que denotam os seus fundamentos críticos.

Em segundo lugar, apareceram quatro diferentes núcleos temáticos, com quatro produções aglutinadas em cada um deles: Prática Docente, EH em espaços públicos, Relações étnico-raciais e Educação Profissional. As análises de práticas docentes evidenciam a preocupação com o preparo do professor de História para lidar com as especificidades da EJA. A abordagem do EH em 
espaços públicos diferenciados explicitou a motivação em romper com a História tradicional e livresca na EJA, ocupando espaços públicos e históricos. Entre a linguagem específica destas produções estavam expressões como "fazeres ordinários", "práxis", "mediação". No conjunto da produção sobre as Relações étnico-raciais foram tratadas tanto a questão indígena quanto a afirmação da identidade negra e revelaram expressões como "política afirmativa", "identidade", "sociabilidades". Sobre a Educação Profissional, verificou-se que as produções centraram-se na categoria "trabalho", apoiada em autores críticos e por isso houve a ocorrência de expressões como "consciência de classe", "formação omnilateral", "formação integral", entre outras.

Em menor número, apareceram os núcleos temáticos comuns a no máximo duas produções (Categoria Memória, Livros Didáticos/Manuais e Ensino pela pesquisa). Outros núcleos temáticos foram abordados por apenas uma produção (EJA no contexto do campo, História de vida dos estudantes, Recursos didáticos, Temas transversais e Questões teórico-epistemológicas). A dispersão em tantos núcleos temáticos é compreensível, analisada a partir da epistemologia de Fleck (2010), pois as produções surgem a partir de uma intensa circulação intercoletiva, acumulando assim, problemas de diferentes ordens: do EH (o que, como e em função do que ensinar), da EJA (heterogeneidade deste público, suas especificidades econômico-sociais, etc.) e da Educação (integração da Educação Profissional à EJA, as legislações educacionais, entre outras questões). Ou seja, observa-se a interlocução entre pesquisadores que procedem de diferentes estilos de pensamento (FLECK, 2010) para enfrentar os problemas relativos ao EH na EJA.

A última categoria analítica permitiu classificar as produções segundo a sua natureza acadêmica. Assim, das 40 produções analisadas 19 foram identificadas como relatos de experiência, 18 como relatos de pesquisa e 03 como ensaios. Os 19 relatos de experiência abrangeram os diferentes níveis da EJA - da alfabetização ao Ensino Médio - e estiveram presentes nos SNH no período de 1971 a 2015. Nesta categoria destacaram-se três relatos de experiência produzidos por professoras do Ensino Superior, a partir da observação de estágios supervisionados de licenciatura em História na modalidade EJA. O volume de relatos de experiências é um indicativo de que os 
professores de História dos diversos níveis da EJA têm demonstrado a preocupação em refletir sobre suas práticas, e também de que estão motivados a compartilhá-las em um espaço criterioso como os SNH.

Os relatos de pesquisa tiveram origem em investigações mais amplas, geradas em Programas de Pós-Graduação Stricto Sensu, bem como em cursos de Especialização da Pós-Graduação Lato Sensu, de Graduação, em Grupos de Estudos ou Projetos de Pesquisa desenvolvidos em IES que contaram com financiamento. Das 18 produções que são relatos de pesquisas, duas apresentaram a característica de serem recortes de teses, cinco de recortes de dissertações, seis de pesquisas realizadas em cursos de especialização, duas tiveram origem em Projetos de Pesquisa, duas no âmbito de Grupos de Estudos e uma produzida em curso de graduação. Tais dados evidenciam que uma comunidade nacional de pesquisadores com foco voltado ao EH na EJA encontrase em processo de constituição.

As outras três produções, que completam o volume de 40 documentos, apresentaram características de "ensaios", pois "São textos em que o autor [...] expõe, teoriza; ainda quando lança mão de dados ou de documentos, não os toma como fonte de pesquisa, mas como exemplos, testemunhos ou referências" (SOARES; MACIEL, 2000, p.57). Tais produções foram socializadas em 2013 e 2015. Trouxeram contribuições ao assumirem um tom de denúncia, apontando o quanto ainda a EJA é secundarizada nas políticas educacionais e ao mesmo tempo anunciando horizontes, cada qual em seu núcleo temático.

Enfim, as produções socializadas no século XXI, além de estarem alinhadas às proposições críticas do campo do $\mathrm{EH}$ e da EJA, apresentaram referências às Diretrizes Curriculares Nacionais para a EJA (Parecer CNE/CEB n011/2000). Assim, apareceram com intensidade expressões que definem a concepção de EJA dos autores, tais como: um processo educativo que considera as "especificidades" dos sujeitos (19 produções); que oportuniza a "autonomia" dos sujeitos (15 produções); uma educação para a "emancipação ou emancipatória" (06 produções); a EJA como um "direito" (18 produções), dentre outras expressões. 


\section{Considerações finais}

A análise do material empírico coletado (40 produções) revelou que a primeira Comunicação localizada nos Anais dos SNH sobre o EH na EJA, produzida à época em que a modalidade era chamada de Madureza, de autoria de dois historiadores e que tratava do desenvolvimento de um recurso didático, não considerava, no processo de elaboração deste material, a experiência e a realidade dos sujeitos a quem ele seria direcionado. Assim, esses pesquisadores dialogavam mais com o campo da História e pouco com o Ensino de História, campo de pesquisa que se encontrava no início de seu processo de constituição naquele período.

Nos Anais do VI SNH, de 1971, tal Comunicação foi considerada em harmonia com o que apregoava a Lei no 5692/71. Portanto, estava em sintonia com um conjunto de pesquisas educacionais, produzidas neste período e orientadas por um estilo de pensamento que ainda vigorava, mas que já mostrava sinais de exaustão, o ensino tecnicista. Segundo Bittencourt (2011, p.90-91), desde os anos 1950 predominou a pedagogia do "tecnicismo educacional". Porém, a partir dos anos 1960, quando surgiu a pesquisa em EH, novos métodos e conteúdos passam a ser propostos para a área, cuja concepção era oposta à neutralidade do professor.

Este período em que um novo modo de conceber e tratar problemas de pesquisa foi proposto, mas não acolhido de forma ampla pela comunidade científica da área, representa o que Fleck (2010) denominou de instauração de um estilo de pensamento. Portanto, foi em um período de transição, marcado por intenso debate intercoletivo de ideias (conhecimentos e práticas) que surgiu 0 primeiro trabalho sobre EH na EJA, nos SNH da ANPUH-Brasil.

Após a ocorrência desta Comunicação de 1971, o estudo revelou uma grande lacuna em relação à produção sobre o EH na EJA entre os Anais dos SNH. No final da década de 1990 elas reapareceram, pautadas em concepções de Educação e de História mais definidas e críticas, em função da influência das proposições construídas pela comunidade de investigadores em $\mathrm{EH}$ nas décadas de 1980 e 1990, bem como pela presença do referencial freiriano e do resgate da concepção de Educação Popular, depois desta proposta ter sido reprimida no 
período da ditadura militar. Esta emergência das concepções críticas de História e de Educação/Ensino foi privilegiada pelo que Fleck (2010, p.88) chamou de "momento social favorável", períodos de grandes transformações no âmbito social mais amplo e que geralmente coincidem com as transformações dos estilos de pensamento, no caso, a redemocratização do país.

No contexto da promulgação da Lei no 9394/96, todas as produções sobre o EH na EJA socializadas nos SNH passaram a reconhecer a importância de se considerar os conhecimentos, a experiência e a realidade dos sujeitos de aprendizagem; a difundir a prática do $\mathrm{EH}$ que parte de problemas do presente; a perceber a importância das fontes diversificadas no EH para ampliar a noção de fonte histórica do estudante, etc.. Diante deste movimento verificou-se que, após o longo período sem produção, o tema voltou ao foco dos pesquisadores com uma perspectiva derivada do estilo de pensamento do $\mathrm{EH}$, da "Era do Repensando" (CAIMI, 2011).

No despontar do século XXI, houve um crescimento expressivo da produção sobre o $\mathrm{EH}$ na EJA socializada nos SNH. Na primeira década, foram localizadas 11 produções, enquanto que a partir da segunda década, (da qual haviam se passado cinco anos, período em que se realizaram apenas três edições do evento), o número mais que duplicou, alcançando 23 produções. A partir daí a análise evidenciou que há uma comunidade nacional de investigadores em EH influenciando a produção científica da área. De forma direta, esta influência se revelou no processo de formação de novos pesquisadores (orientações de pesquisas), como também de acolhimento de pesquisas sobre o $\mathrm{EH}$ na EJA em ST que coordenavam. De forma indireta, a ação desta comunidade de pesquisadores se evidenciou no grande volume de referenciais teóricos deste campo compartilhados pelos autores da produção. Neste século, portanto, a tendência dos referenciais críticos se manteve.

Foram muitas experiências significativas socializadas, que podem potencializar o $\mathrm{EH}$ na EJA, não sendo tomadas como fórmulas ou receitas, mas como pontos de partida para debates e reinvenções. Contudo, a análise da produção também evidenciou alguns silenciamentos, como por exemplo, a ausência de discussões sobre gênero, em voga tanto no campo da Educação como no da História, bem como presentes na realidade escolar. 
Além disso, verificou-se a pouca problematização acerca do público jovem que hoje tem constituído a maioria dos matriculados na EJA e também não foram localizadas pesquisas que tenham como sujeitos os idosos que frequentam a modalidade. A análise de livros didáticos figurou em apenas uma pesquisa; o mesmo ocorreu com a questão dos manuais. Os recursos didáticos, que foram abordados em 1971, não se fizeram mais presentes e a despeito de estarmos na era digital, não foram localizadas reflexões sobre o uso das tecnologias no $\mathrm{EH}$ na EJA. Verificou-se, enfim, que a grande maioria dos temas ainda carece da atenção dos pesquisadores.

Além de todas estas frentes de pesquisa possíveis e necessárias, o conjunto de produções analisadas apontou a existência de uma comunidade de investigadores estabelecendo os primeiros movimentos de organização acadêmica em torno deste objeto. Existem pesquisas de Pós-Graduação, Grupos de Estudos e Projetos de Pesquisa que abordaram o EH na EJA, e um ST específico no SNH de 2015. Todo esse movimento é muito significativo, visto através das considerações que Fleck (2010) fez sobre a estrutura social do universo científico.

Os protagonistas deste movimento foram os proponentes de STs específicos da EJA: Alessandra Nicodemos, Paulo Eduardo Dias de Mello e Raimundo Nonato Araújo da Rocha. Além destes, dentre os 51 autores, foram identificados 16 que têm um vínculo maior com a EJA, e que por isso, apresentam maior tendência em continuar produzindo sobre o EH na EJA (um Pós-Doutor; seis Doutores; dois doutorandos; quatro Mestres; um mestrando; um especialista e um graduado). Neste grupo, destacou-se a atuação de José Raimundo Lisbôa da Costa e de João Carlos Ribeiro de Andrade, ambos orientados por Lana Mara de Castro Siman. O primeiro porque sua tese foi uma das pioneiras na abordagem do EH na EJA, e o segundo, por sua contribuição com duas publicações nos SNH. Outra pesquisadora que se sobressaiu foi Claudia Mendes de Abreu, com duas publicações caracterizadas como relato de pesquisa: uma de especialização e outra de mestrado.

A conquista de um ST próprio em 2015 indicou que nos últimos anos, o coletivo de pesquisadores em EH na EJA esforçou-se para viabilizar e intensificar a circulação intracoletiva de ideias, sinais claros, segundo Fleck (2010), da 
extensão dos estilos de pensamento vigentes na área. Caso seja mantido, este espaço permitirá direcionar cada vez mais o olhar destes pesquisadores para os problemas urgentes da modalidade, favorecerá a convergência de seus pressupostos teóricos e metodológicos, criando assim, condições para a emergência e consolidação de uma comunidade nacional de investigadores do EH na EJA, a exemplo de outras áreas do conhecimento que foram instituídas e consolidadas em dinâmica semelhante.

\section{Referências}

BARDIN, Laurence. Análise de Conteúdo. Lisboa: Edições 70, 2002.

BITTENCOURT. Circe Maria Fernandes. Ensino de História: fundamentos e métodos. 4 ed. São Paulo: Cortez, 2011.

BRASIL. Relatório Educação para Todos no Brasil, 2000-2105. Brasília: MEC, 2014.

CAIMI, Flávia Eloisa. Conversas e controvérsias: o ensino de História no Brasil (1980-1998). Passo Fundo: UPF, 2001.

CARA, Daniel. A Educação de Jovens e Adultos (EJA) é tratada de maneira míope e desumana. UOL Educação: 26 ago. 2014. Colunas. Disponível em: <http://edu cacao.uol.com.br/colunas/daniel-cara/2014/08/26/o-maior-desafio-do-pne-e-aeducacao-de-jovens-e-adultos.htm>. Acesso em: Nov. 2014.

COSTA, Aryana Lima; OLIVEIRA, Margarida Maria Dias de. O Ensino de História como objeto de pesquisa no Brasil: no aniversário de 50 anos de uma área de pesquisa, notícias do que virá. Sæculum - Revista de História, n.16, João Pessoa, p.147-160, jan-jul. 2004. Disponível em: <http://www.biblionline.ufpb. br/ojs/index.php/srh/article/viewFile/11378/6492>. Acesso em: Set. 2015.

DELIZOICOV, Demétrio. Pesquisa em Ensino de Ciências como Ciências Humanas Aplicadas. Caderno Brasileiro de Ensino de Física, Florianópolis, v. 21, ago. 2004. p.145-175. Disponível em: <https://periodicos.ufsc.br/index.php/fisica/article/ wiew/6430>. Acesso em: Out. 2015.

FERREIRA, Norma Sandra de Almeida. As pesquisas denominadas "estado da arte". Educação e Sociedade, Campinas, v. 23, n. 79, p. 257-272, Ago. 2002. Disponível em: <http://www.scielo.br/scielo.php?script=sci_arttext\&pid=S010 $173302002000300013 \& \mathrm{ng}=\mathrm{en \& nrm}=$ iso $>$. Acesso em: Ago. 2015.

FLECK, Ludwik. Gênese e desenvolvimento de um fato científico. Belo Horizonte: Fabrefactum, 2010.

GADOTTI, Moacir. 50 anos de Angicos: um sonho interrompido a ser retomado. Educatrix, São Paulo, ano 4, n.2, p.26-31, 2014. 
LÖWY, Ilana. Fleck no seu tempo, Fleck no nosso tempo: Gênese e desenvolvimento de um pensamento. In: CONDÉ, Mauro Lúcio Leitão (Org.). Ludwik Fleck: estilos de pensamento na ciência. Belo Horizonte: Traço Fino, 2012. p.11-33.

MESQUITA, Ilka Miglio de. Memórias/identidades em relação ao ensino e formação de professores de História: diálogos com fóruns acadêmicos nacionais. 2008. Tese (Doutorado em Educação) - Universidade Estadual de Campinas, Campinas, 2008.

PARECER CNE/CEB no 11/2000 - Diretrizes Curriculares Nacionais para a Educação de Jovens e Adultos. Disponível em: <http://www.cee.ms.gov.br>. Acesso em: Ago. 2015.

REIS, Carlos Eduardo dos. História Social e Ensino. Chapecó: Argos, 2001.

ROCHA, Claudia Smuk da. O estado do conhecimento sobre o Ensino de História na EJA: um estudo a partir dos Anais dos Simpósios da Associação Nacional de História (ANPUH-Brasil) 1961-2015. 2016. Dissertação (Mestrado em Educação) - Universidade Federal da Fronteira Sul, Chapecó, 2016.

ROMANOWSKI, Joana Paulin; ENS, Romilda Teodora. As pesquisas denominadas do tipo "estado da arte" em Educação. Diálogo Educacional, Curitiba, v. 6, n.19, p.37-50, set./dez. 2006. Disponível em: <http://www2.pucpr.br/reol/pb/index. php/dialogo?dd1=237\&dd99=view\&dd98=pb> . Acesso em: Ago. 2015.

SCHÄFER, Lothar; SCHNELLE, Thomas. Fundamentação da perspectiva sociológica de Ludwik Fleck na teoria da ciência. (Introdução). In: FLECK, Ludwik. Gênese e desenvolvimento de um fato científico. Belo Horizonte: Fabrefactum, 2010. p. 1-36.

SLONGO, Iône Inês Pinsson. A produção acadêmica em Ensino de Biologia: um estudo a partir de teses e dissertações. 2004. Tese (Doutorado em Educação) Universidade Federal de Santa Catarina, Florianópolis, 2004.

SOARES, Magda; MACIEL, Francisca. Alfabetização. Brasília: MEC/Inep/Comped, 2000. Disponível em: <http://www.dominiopublico.gov.br/download/texto/me00 0084.pdf>. Acesso em: Ago.2015.

TRIVIÑOS, Augusto Nibaldo Silva. Introdução à Pesquisa em Ciências Sociais: a pesquisa qualitativa em Educação. São Paulo: Atlas, 1987.

Recebido em 17 de novembro de 2018

Aprovado em 31 de agosto de 2020 